\title{
Description of the acoustical interaction and synchronization between duetters of the Large- footed Finch (Pezopetes capitalis)
}

\section{Carla Trejos-Araya \& Gilbert Barrantes}

To cite this article: Carla Trejos-Araya \& Gilbert Barrantes (2017): Description of the acoustical interaction and synchronization between duetters of the Large-footed Finch (Pezopetes capitalis), Bioacoustics, DOI: 10.1080/09524622.2017.1303792

To link to this article: http://dx.doi.org/10.1080/09524622.2017.1303792

曲 Published online: 10 Apr 2017.

Submit your article to this journal ¿

Q View related articles $\longleftarrow$

View Crossmark data ¿ 


\title{
Description of the acoustical interaction and synchronization between duetters of the Large-footed Finch (Pezopetes capitalis)
}

\author{
Carla Trejos-Arayaa ${ }^{\mathrm{a}, \mathrm{b}}$ and Gilbert Barrantes ${ }^{\mathrm{a}}$ \\ aEscuela de Biología, Universidad de Costa Rica, San Pedro de Montes de Oca, Costa Rica; ${ }^{\text {b} E s c u e l a ~ d e ~ C i e n c i a s ~}$ \\ Naturales y Exactas, Instituto Tecnológico de Costa Rica, Santa Clara, Costa Rica
}

\begin{abstract}
Duets are highly coordinated acoustical displays produced by two individuals. Studying the structure of duet songs and its causes is essential to understand the ecological role and evolution of this form of communication. Our goals in this study were to describe the structure of the duet of the Large-footed Finch, the temporal synchronization of each individual, and to test the effect of provoked (playback) duets. We recorded birds at Cerro de la Muerte, Costa Rica and simulated territory intrusions using playback trials. The duet of this species consisted of overlapping notes between both members of a mated pair, which were emitted either randomly or periodically. Temporal synchronization was similar between both individuals in a mated pair. Both partners adjust the silent intervals between notes in response to the duration of its partner's note. The high frequency of the second part of the duet of this species decreased with time and the second individual, in duetting this part, not only synchronized its notes temporally with the first individual, but also synchronized the high frequency. The high frequency of the first note the second individual sung was a bit lower than the previous note sung by the first individual. Finally, birds responding to provoked duets produced duets with higher frequency and higher rate of notes compared to unprovoked duets. Our results provide information on the temporal and frequency synchronization in duets of an endemic emberizid and provide new information about a less reported vocal behaviour in bird duets, the acoustic frequency coordination.
\end{abstract}

\section{ARTICLE HISTORY}

Received 20 April 2016

Accepted 21 February 2017

\section{KEYWORDS}

Emberizidae; endemic bird; acoustic frequency coordination; temporal synchronization; overlapping

\section{Introduction}

In nearly 450 bird species (40\% of bird families), both males and females vocalize with temporal coordination to produce a stereotyped acoustic pattern known as a duet (Farabaugh 1982; Logue 2007; Hall 2009). The literature on duets has rapidly accumulated, particularly on their acoustical structure (Brumm \& Slater 2007; Hall 2009; Douglas \& Mennill 2010; Dahlin \& Benedict 2013) and functions (ie Farabaugh 1982; Langmore 1998; Hall 2004; Logue 2005). 
One characteristic of the duet is the temporal coordination (synchronization), as most duetters engage together in a highly coordinated acoustic display (Dahlin \& Benedict 2013). It has been proposed that the biological meaning of this coordination is associated with either individual quality (Hall \& Magrath 2007), or to avoid misdirected aggression when pairs are involved in territorial encounters (Farabaugh 1982), or to avoid signal masking (Brumm \& Slater 2007), though these hypotheses might not be mutually exclusive.

Information on duets in species of the family Emberizidae is scarce. Farabaugh (1982) reported two emberizid duetting species for the Panamanian region and Sandoval et al. (2016) described the duet of the White-eared Ground-sparrows for Costa Rican populations. At present at least eight duetting species have been reported in the family Emberizidae, including the Large-footed finch (Trejos-Araya \& Barrantes 2014). Detailed studies of the acoustic structure and function of duets are lacking for most of these duetting emberizids, including the Large-footed finch (Trejos-Araya \& Barrantes 2014). This is a species endemic to the highlands of Costa Rica and western Panama. In Costa Rica, it is a common resident in the highlands of Central and Talamanca Cordilleras (Stiles \& Skutch 2007).

Considering the lack of information on the structure of duets and the possible role of each mate of Large-footed finches during duetting, we addressed three goals in this study. First, to determine the degree of temporal synchronization of each individual of the pair during duetting. Second, to test if individuals were able to modify the timing of their notes during duetting in response to changes in their mates' timing. Finally, to describe if duetting pairs modify the acoustic structure of their duets in response to different playback duets. Our hypothesis here is that pairs would change one or more parameter of their duet's acoustic structure in response to playback duets with different acoustic structure; for example, for playback duets with longer duration, we expect a more intense duetting response.

\section{Material and methods}

\section{Study population}

We conducted this study in the Estación Biológica Cerro de la Muerte $\left(09^{\circ} 34^{\prime} \mathrm{N} ; 83^{\circ} 41^{\prime} \mathrm{W}\right.$, at 3150 m elevation) from March 2011 to October 2012. The study site is characterized by the presence of an oak forest (Quercus costaricensis), with an understory dominated by dense thickets of bamboo (Chusquea spp.) disperse bushes and small trees.

In total we recorded 12 mated pairs. We mist netted and colour-banded at least one individual from six of this 12 mated pairs which allowed us to identify and follow them within their territory. The other six mated pairs were not banded. Pairs in this species typically maintain territories for at least two years, and forage within their territories (Trejos-Araya \& Barrantes 2014). Thus, to avoid recording other birds, we followed each of these pairs for two weeks and recorded them in their territories.

\section{Playback experiments}

For playback experiments, we used each of three different playbacks containing only duets. Two of them (LCH 12-001 and LCH 12-003) are deposited at the Laboratorio de Bioacústica, Escuela de Biología, Universidad de Costa Rica and were recorded in Barva National Park (73 km away from the study site). The third playback was recorded in 2009 at Estacion 
Biologica Cerro de la Muerte (approx. $500 \mathrm{~m}$ away from the study site). These playback duets varied in their duration, frequency of notes/time and acoustical frequencies (low and high frequency, maximum frequency).

We assigned each of the playbacks randomly to the corresponding pair and did not play each more than three times, to avoid habituation to the playback song and a consequent affectation on their response. All trials were conducted between 5:30 h and 7:00 h, the period of highest acoustic activity of the Large-footed finch (unpubl. data). For each pair, we only used one of the playbacks per day to ensure that the responses recorded were a consequence of that particular playback.

We used a Sennheiser ME66 directional microphone and a Marantz PMD 661 solid state digital recorder to record the duets of our focal species. All digital recordings were saved as uncompressed mono WAV files (48-bit, $44 \mathrm{kHz}$ ).

\section{Analysis of vocalizations}

We analysed all playbacks and recordings using Raven pro 1.4 (Bioacoustics Research Program 2011). We recorded at least two unprovoked duets (natural duets) from all banded pairs during one hour beginning at 4:40 h, the time when mated pairs start to sing (unpubl. data) around the roosting and nesting sites (L. Sandoval com. pers).

For all pairs, we recorded and analysed at least two duet responses to each of the three playbacks used. The purpose of several recordings of unprovoked and provoked duets was to include some possible variation in the analyses.

The first step to describe the duet structure was to assign the notes to the corresponding individual in a pair, to do this we directed the microphone to one individual (usually the banded one when banded pairs were being recorded) as they were responding to the playback. Though this microphone is not strongly directional, it was still possible to distinguish on the spectrograms the two individuals' duetting, unless both individuals sang very close together, but we did not have this particular situation. This method has been proved to be effective in separating the song of a duetting pairs (Graham et al. 2016). In addition, we made verbal and written notes to indicate towards which of the two individuals the microphone was directed. In all cases, the spectrogram of the bird singing directly towards or closer to the microphone was darker (higher sound intensity), than that of the other bird, we noted this pattern on all recordings analysed. Furthermore, we were able to video record (using a Sony HDR-SR1 1 camcorder) three banded territorial birds, each from a different mated pair, that provided us with visual checking that mated individuals sang together during the whole duet duration. This species' duet consists of a sequence of antiphonal, highly coordinated notes sang with a stereotyped acoustic pattern (Trejos-Araya \& Barrantes 2014).

Considering that there were two distinct groups of notes in the duet of Large-footed finches, for all analyses we divided all duets into two sections (Figure 1). We measured for each section of the duet two temporal acoustical variables: duration of each note and the silent interval between notes. The silent interval corresponded to the time between the end of the note of one individual and the beginning of the next note corresponding to its partner (e.g. the time it takes for one individual to respond to its partner). When a temporal overlap occurred, we measured the overlapping time and assigned it as a negative value to differentiate it from non-overlapping notes. Both silent interval and overlapping time were 


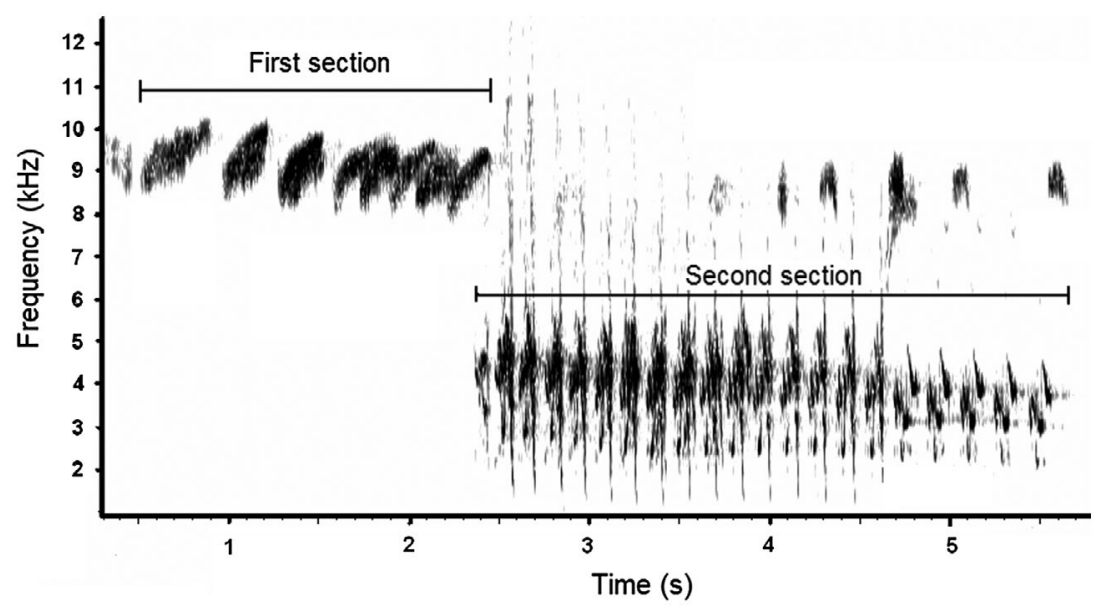

Figure 1. Sound spectrogram of a duet of the Large-footed finch indicating the two sections used to analyse temporal overlapping.

considered as parameters for temporal coordination, considering that coordination can be achieved whether a pair overlapped their notes or not during duetting.

We defined a note as a discrete sound that could be frequency $(\mathrm{Hz})$ and/or time modulated and that can be separated temporally or in frequency from other notes. We also defined synchronization as the temporal coordination of the notes in a duet sang by both birds. Temporal synchronization could then occur whether or not notes overlap in the duet.

\section{Statistical analysis}

Duets of Large-footed finch are composed of repetitions of similar notes, which are emitted with apparently regular time intervals (periodicity). Given this periodical nature, it is possible to represent the notes of the duet with a sine function. To calculate the periodicity of the notes for one individual relative to the other individual in the duet of Large-footed finches (reference individual), we used circular statistical calculations following the methods outlined in Zar (2010) and the modified equation (Equation 1) used by Maynard et al. (2012). This equation includes triads of notes as the sampling unit. The triads are composed of a sequence of notes in which the first $\left(R_{1}\right)$ and third $\left(R_{2}\right)$ note of the triad belongs to one bird (e.g. initiator bird) and the second note $(X)$ belongs to the second bird (e.g. answering bird). Then the time between the beginning of $R_{1}$ and the beginning of $X$, and between the beginning of $R_{2}$ and the beginning of $R_{1}$ are measured and included in the equation $A$, which transform these time intervals to degrees.

$$
A=\frac{360\left(X-R_{1}\right)}{R_{2}-R_{1}}
$$

For instance, if the note of the answerer is exactly halfway between the two notes of the initiator, the value of $A$ is $90^{\circ}$. We calculated a mean value of $A$ for the initiator and answerer within each pair. 
For each value of $A$ we calculated the sine and cosine to obtain the $r$-vector, which represents the periodicity between the time the notes of both individuals are emitted: $r$-vector varies from 0 to 1 , where a value of 0 indicates absence of periodicity, while a value of 1 indicates that the notes in a duet were sung with strict periodicity. We then calculated the mean angle for each duet sang by each pair and used it in a second order sample parametric analysis (Zar 2010, p. 645) to statistically test whether or not the time between notes of the duet are periodically for one or both of the duetting birds. We performed circular statistics analyses using Microsoft Excel 2003. Pairs with a probability higher than 0.05 were considered to be singing their duetting section periodically.

We obtained the mean and the correspondent standard deviation of silent interval time or overlapping time for each individual in a mated pair to analyse their temporal synchronization. For this, we considered as the first individual the one that initiated the duet, and as the second individual the one responding to the first individual's notes. Then we calculated the coefficient of variation (CV) of each individual, of a mated pair, within both sections of the duet. We used the $\mathrm{CV}$ values to test with a paired $T$-test if the temporal synchronization was similar between individuals on a given section of the duet. We considered individuals with lower $\mathrm{CV}$ values as more temporally coordinated given that low $\mathrm{CV}$ values implies less variation in their timing.

To determine whether each member of a mated pair is capable of adjusting its timing (duration of a note and silent intervals), we regressed the duration of notes of one individual against silent intervals of its partner.

In the second section of all duets, the acoustic frequency (e.g. high frequency in $\mathrm{kHz}$ ) of the notes seemed to decrease with time (e.g. high frequency decreases with time) (Figure 1). This acoustic behaviour was also seen when an individual sang alone the same notes of the duet. To determine if the frequency of notes changed with time, we measured the high frequency of each individual note and then compared it against the order in which each note was sung, one being the first note of the section of the duet analysed. We did not include low frequency because the lower limit of each note was difficult to define in the spectrogram.

To compare the reduction in high frequency between individuals of a mated pair, we regressed the order of the notes against the high frequency for each bird and then compared the slopes and intercepts between sexes. Regressions were calculated for those sections of the duet in which both birds participate in the duet.

We compared the acoustic structure of natural duets with that of provoked duets to evaluate the potential effect of playbacks on the way birds sing their duet in a natural context. For this analysis, we used generalized linear mixed models (library nlme) for four response variables: (1) Duration of duet, (2) High frequency, (3) Maximum frequency and (4) the ratio between number of notes and the duration of the duet. The first variable was measured for the entire duet, and the last three variables were measured for each section of the duet. We included in the analysis two predictor categorical variables: (1) Pair, and (2) Treatment, which involved natural and provoked duets, and included the playback used in each trial as a random factor. These analyses were performed using R software (R Core Team 2012).

\section{Results}

During duetting, on the first section of the duet, five pairs $(N=12)$ sang the notes of the first section of the duet periodically. For the second section, five pairs $(N=10)$ sang their 
notes periodically, the remaining individuals in the other five pairs sang their notes randomly with respect to each other. We found only one pair that sang both sections of the duet periodically, and two pairs in which both individuals sang their notes randomly (Table 1).

The synchrony measured by the CV was similar for both individuals on the duet's sections $(t=-0.31, \mathrm{df}=11, p=0.759$ for the first section and $t=0.19, \mathrm{df}=10, p=0.853$, for the second section). CVs values were low for both individuals in a mated pair: on the first section the CV for the first individual was $0.35 \pm 0.18$ and for the second individual it was $0.33 \pm 0.16$. For the second section of the duet the CV of the first individual was $0.33 \pm 0.22$ and $0.34 \pm 0.31$ for the second individual.

For the first section of the duet ( $N=39$ duets), the first individual overlapped with $11-100 \%$ of the notes of the second individual. This represented a mean overlapping time of $0.762 \pm 0.623 \mathrm{~s}$ of the singing time of the first individual and corresponded to $34 \%$ of the mean duration of the notes sung by this individual in this section. The second individual overlapped with $17-100 \%$ of the notes of the first individual, with a mean overlapping time of $0.568 \pm 0.540$ s of the singing time for the second individual, representing $27 \%$ of mean duration of notes sung in the first section.

For the second section of the duets $(N=28)$, only the second individual overlapped between 79 and $100 \%$ of the notes of the first individual. The overlapped time varied greatly in these individuals $(0.54 \pm 0.86 \mathrm{~s})$ and this time corresponded to $33 \%$ of the mean duration of its notes. In addition, the duration of notes and the silent intervals decreased for both individuals (first individual $N=10$, second individual $N=9$ ) along the second section of the duet (Table 2).

In seven out of nine pairs, the high frequency of the notes in the second section of the duet decreased from the first to the last note (Figure 2). In six of these nine pairs, the high frequency decreased similarly (similar slopes) for both mates as the duet progressed (Table 3).

In response to playbacks, Large-footed finches increased the high frequency of the second section of duets in comparison with the natural duets (unprovoked duets), maximum frequency in both sections of the duet, and the number of notes in the first section while responding to playback 2 , and in response to playback 1 on the second section. The duration of duets did not change in response to playbacks (Figures 3-5; Table 4).

Table 1. Results of the circular statistical analysis for each section of duets of the Large-footed finch (Pezopetes capitalis).

\begin{tabular}{|c|c|c|c|c|c|c|c|c|c|c|}
\hline \multirow[b]{2}{*}{ Pair code } & \multicolumn{5}{|c|}{ First section of the duet } & \multicolumn{5}{|c|}{ Second section of the duet } \\
\hline & $F$-value & DF & $p$ & $r$-vector & $\begin{array}{l}\text { Mean } \\
\text { angle }\end{array}$ & $F$-value & DF & $p$ & $r$-vector & $\begin{array}{l}\text { Mean } \\
\text { angle }\end{array}$ \\
\hline 1 & 2.97 & 2,29 & 0.0668 & 0.29 & 104 & 5.86 & 2,49 & 0.00521 & 0.26 & 149 \\
\hline 2 & 1.18 & 2,12 & 0.34 & 0.26 & 167 & 3.07 & 2,19 & 0.0701 & 0.36 & 146 \\
\hline 3 & 0.88 & 2,22 & 0.428 & 0.19 & 104 & 6.59 & 2,32 & 0.00402 & 0.40 & 173 \\
\hline 4 & 6.08 & 2,28 & 0.0064 & 0.38 & 161 & 1.15 & 2,62 & 0.324 & 0.13 & 176 \\
\hline 5 & 9.67 & 2,30 & $<0.001$ & 0.48 & 152 & 6.25 & 2,37 & 0.00458 & 0.41 & 127 \\
\hline 6 & 7.12 & 2,24 & 0.00373 & 0.47 & 165 & - & - & - & - & - \\
\hline 7 & 27.87 & 2,25 & $<0.001$ & 0.59 & 150 & 28.02 & 2,60 & $<0.001$ & 0.50 & 153 \\
\hline 8 & 40.06 & 2,20 & $<0.001$ & 0.72 & 142 & 0.97 & 2,40 & 0.387 & 0.13 & 170 \\
\hline 9 & 0.68 & 2,4 & 0.55 & 0.30 & 172 & - & - & - & - & - \\
\hline 10 & 0.53 & 2,16 & 0.60 & 0.19 & 134 & 227.87 & 2,20 & $<0.001$ & 0.85 & 115 \\
\hline 11 & 20.59 & 2,25 & $<0.001$ & 0.58 & 168 & 0.59 & 2,35 & 0.558 & 0.13 & 136 \\
\hline 12 & 4.17 & 2,17 & 0.0336 & 0.33 & 12 & 0.68 & 2,15 & 0.519 & 0.22 & 83 \\
\hline
\end{tabular}

Note: Some pairs timed their notes randomly, and others periodically. 
Table 2. Relationship between the duration of the notes of each sex vs. the silent interval of its partner or overlapping time in duetting pairs of the Large-footed finch.

\begin{tabular}{|c|c|c|c|c|c|c|c|c|}
\hline Pair code & $\begin{array}{l}\text { Silent } \\
\text { interval of } \\
\text { the second } \\
\text { individual } \\
\text { vs. duration } \\
\text { of notes } \\
\text { of the first } \\
\text { individual } \\
\left(R^{2} \text {-value) }\right.\end{array}$ & $\begin{array}{l}\text { Regression } \\
\text { slope }\end{array}$ & DF & $p$ & $\begin{array}{l}\text { Silent } \\
\text { interval of } \\
\text { the first } \\
\text { individual } \\
\text { vs. duration } \\
\text { of notes of } \\
\text { the second } \\
\text { individual } \\
\text { ( } R^{2} \text {-value) }\end{array}$ & DF & $\begin{array}{l}\text { Regression } \\
\text { slope }\end{array}$ & $p$ \\
\hline 1 & 0.01 & 0.09 & 105 & 0.400 & 0.18 & 102 & -0.50 & $<0.0001$ \\
\hline 2 & 0.06 & -60.19 & 38 & 0.132 & 0.02 & 36 & -0.16 & 0.339 \\
\hline 3 & 0.22 & -0.54 & 60 & 0.000138 & 0.12 & 57 & -0.37 & 0.00673 \\
\hline 4 & 0.18 & -0.36 & 99 & $<0.0001$ & 0.25 & 102 & -0.50 & $<0.0001$ \\
\hline 5 & 0.26 & -0.53 & 90 & $<0.0001$ & 0.10 & 77 & -0.21 & 0.00444 \\
\hline 6 & 0.15 & -0.54 & 31 & 0.0261 & 0.30 & 30 & -0.57 & 0.00115 \\
\hline 7 & 0.12 & -0.24 & 95 & 0.00041 & 0.23 & 89 & -0.33 & $<0.0001$ \\
\hline 8 & 0.25 & -0.34 & 66 & $<0.0001$ & 0.27 & 64 & -0.30 & $<0.0001$ \\
\hline 10 & 0.30 & -0.74 & 49 & $<0.0001$ & 0.34 & 39 & -0.53 & $<0.0001$ \\
\hline 11 & 0.49 & -0.64 & 69 & $<0.0001$ & 0.27 & 65 & -0.41 & $<0.0001$ \\
\hline 12 & 0.11 & -0.36 & 38 & 0.0382 & 0.24 & 39 & -0.62 & 0.00126 \\
\hline
\end{tabular}

Note: Individuals reduce their silent intervals when their partners increased the duration of its notes.

\section{Discussion}

Most studies in duetting birds focus on coordination in timing and coordination of song types (see Farabaugh 1982; Brumm \& Slater 2007; Hall 2009; Maynard et al. 2012), so this study reveals new information on these areas but also about a less reported vocal behaviour in bird duets: acoustic frequency coordination. In duets of Large-footed finches, some pairs within a territorial pair sing their notes temporally randomly and others periodically, in both cases with high temporal overlapping between notes. A similar temporal synchronization between members of a mated pair was also reported by Marshall-Ball et al. (2006), in pairs of plain wrens (Cantorchilus modestus) that had been together for several years.

It has often been proposed that temporal synchrony may serve different functions within duets. For instance, an individual can test its partner's capacity to synchronize with its own temporal variation and use this information as an honest signal of its partner's general condition, of its vocal abilities (Hall 2004) and attentiveness (Smith 1994). Moreover, duetting synchrony may indicate better territory defenders to their neighbours by creating a more threatening territorial response (Hall \& Magrath 2007; Hall 2009). Furthermore, synchrony has been considered as an important parameter to avoid misdirected aggression, when pairs are involved in territorial encounters, by providing information about individual and sexual identity (Farabaugh 1982).

Large-footed finches duetted when a pair reunited, when members of another pair approach their territory or when they are provoked by playbacks, showing in this case an apparent aggressive behaviour against the source of sound and singing closer to each other (Trejos-Araya \& Barrantes 2014). Even though the goal for this study was not to determine the functions of duetting and the role of synchrony on this species, we believe it is important to consider all the possible implications of temporal synchrony on a territorial species.

In some contexts (e.g. contact signals, long distance singing), birds tend to avoid overlapping in acoustical signals to reduce acoustical masking by another bird (Todt \& Naguib 

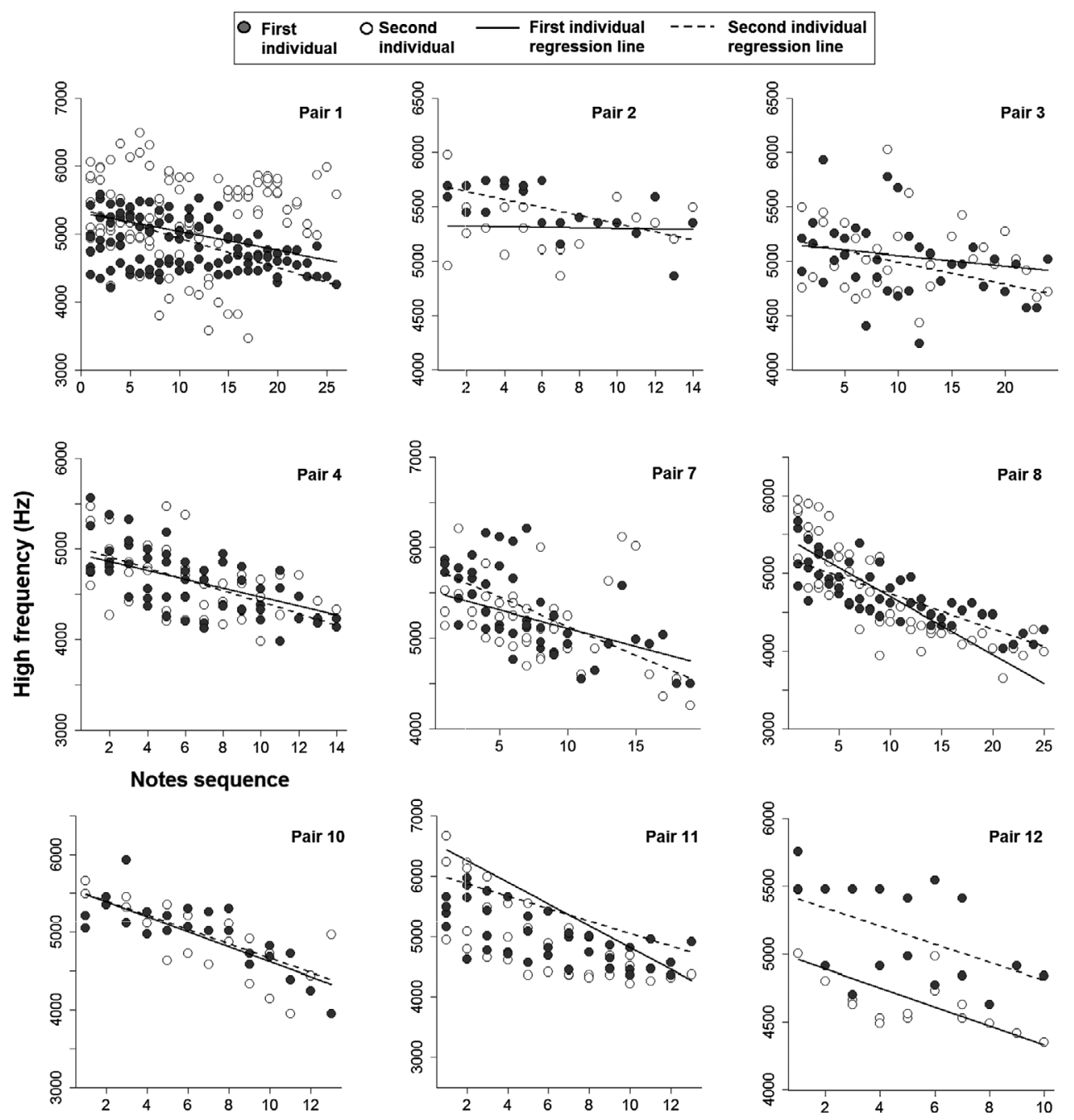

Figure 2. Relationship between the sequence of notes of each individual in the second section of duets of Large-footed finches and their high frequency $(\mathrm{Hz})$.

2000; Searcy \& Beecher 2009). However, if a bird either sings its notes temporally randomly within a given time window (e.g. a silent period between the partner's notes), or the duration of the note is longer than the silent period between notes of its partner, overlapping can be inevitable (Todt \& Naguib 2000; Naguib \& Mennill 2010). Hence, if a duetting individual of Large-footed finch has a short period of time to response between two consecutive notes of its duetting partner and notes are emitted randomly in some of these birds, is highly probable that notes of both members of a territorial pair overlap within a duet. However, the overlapping time is relatively low in this species, likely allowing signals of both individuals to be heard by neighbours or potential competitors.

The changes in silent intervals detected along the duet of Large-footed finches could be a mechanism to adjust to variation in duration of the notes of partners and thus to reduce 


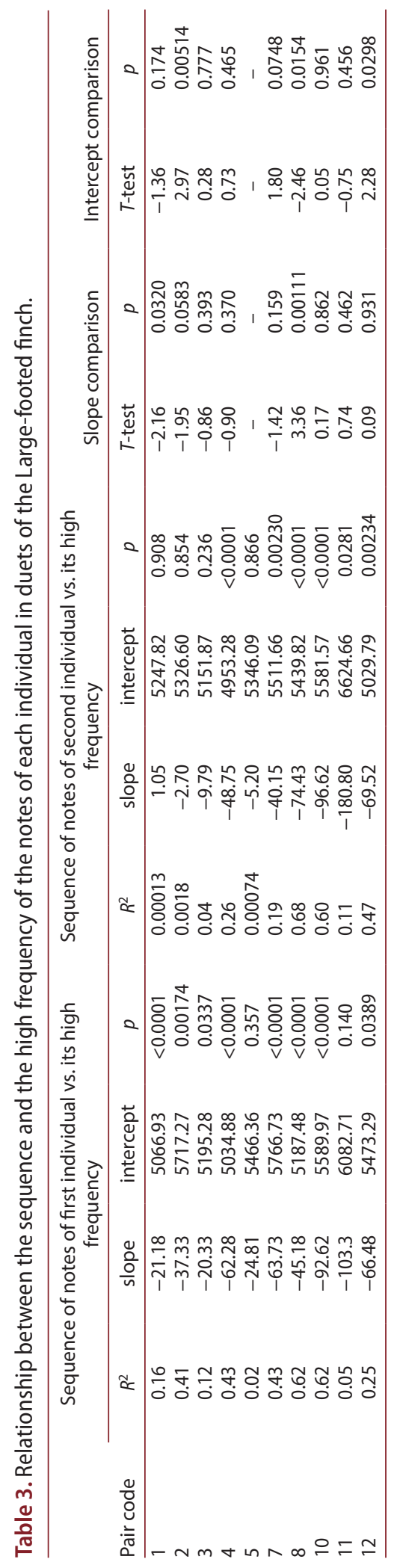




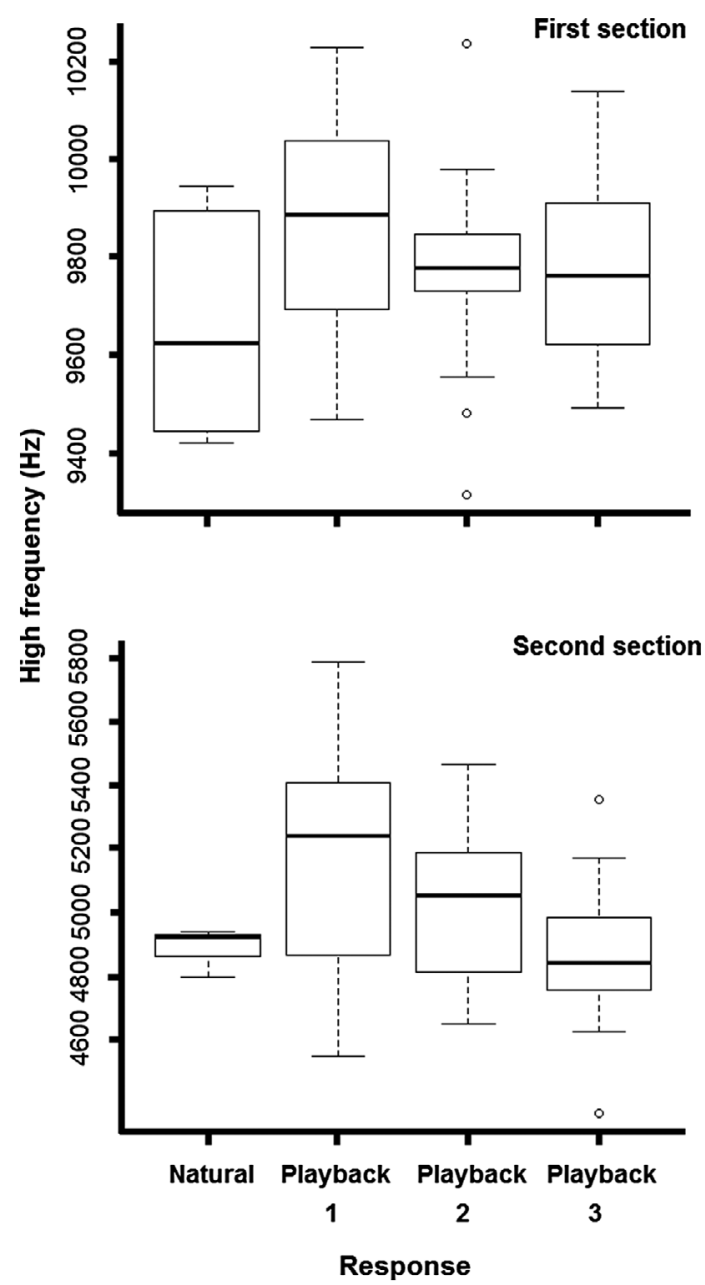

Figure 3. Variation in the high frequency of notes in natural duets (unprovoked duets) and duets provoked by playbacks in the Large-footed finch.

Note: Asterisk (*) indicates $p$-value $<0.05$ when comparing playbacks against natural duets.

acoustical overlap. However, Todt and Naguib (2000) suggested that the degree of overlap indicates the state or status (e.g. interactive state) of an individual.

The biological importance of producing duets with overlapping notes could also be related to producing more threatening signals than those signals produced with a solo song by one individual or non-overlapping duets, because acoustical signals could be reinforced with the combination of notes of both mated birds (Todt \& Naguib 2000, Fitzimmons et al. 2008). This would support the function of joint resources defence of duets (Hall 2004).

Our results indicate that, in addition to temporal coordination, Large- footed finch pairs are capable of coordinating the frequency of the notes in a duet. Our data suggested that each member in a duetting pair apparently adjusts the high frequency of each note to match the frequency of the previous note of its partner and at the same time slightly reduce the high frequency of each note to maintain the decreasing pattern of the high frequency of the duet (Figure 2: pairs 4 and 10). Coordination in frequency, referred as frequency 


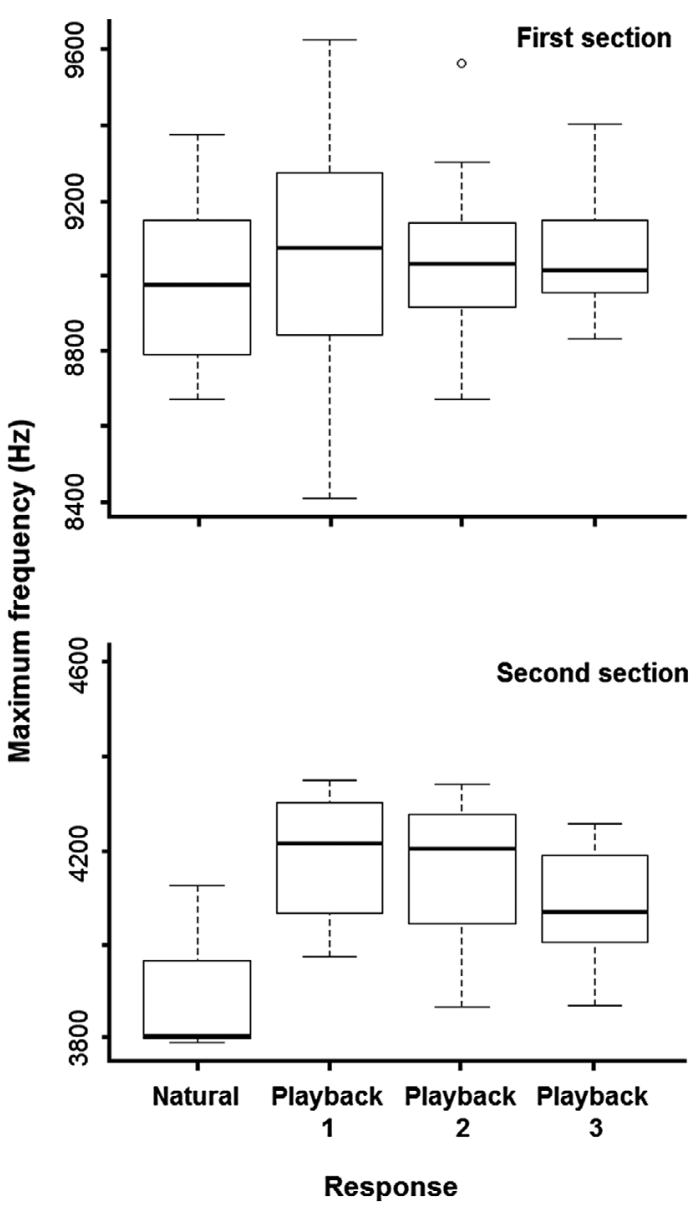

Figure 4. Variation of the maximum frequency of notes in natural duets (unprovoked duets) and duets provoked by playbacks in the Large-footed finch.

Note: Asterisk $(*)$ indicates $p$-value $<0.05$ when comparing each playback against natural duets.

matching by most authors, has been reported in other taxonomic groups. For example in mosquitoes, Cator et al. (2009) reported that males and females of Aedes aegypti were able to coordinate their harmonics to match those of the opposite sex, and Pennetier et al. (2010) found that individuals of Anopheles gambiae could match flight-tone harmonic frequencies for species and mate recognition.

This type of acoustic frequency coordination for Large-footed finches likely requires a high level of attentiveness and an extraordinary neural capacity that allow fine/scale adjustments on a scale of milliseconds to perceive and produce highly coordinated duets in both timing and frequency (Hall 2009). The reduction in high frequency presented by both individuals in a mated pair as the second section of the duet progresses could also be produced by fatigue of muscles associated to song production (Suthers et al. 1999). The frequency could decrease as fatigue increases. However, it is unlikely that the second bird that began to sing after the first had initiated this part of the duet begins singing with a similar level of muscular fatigue compared to the first bird. 


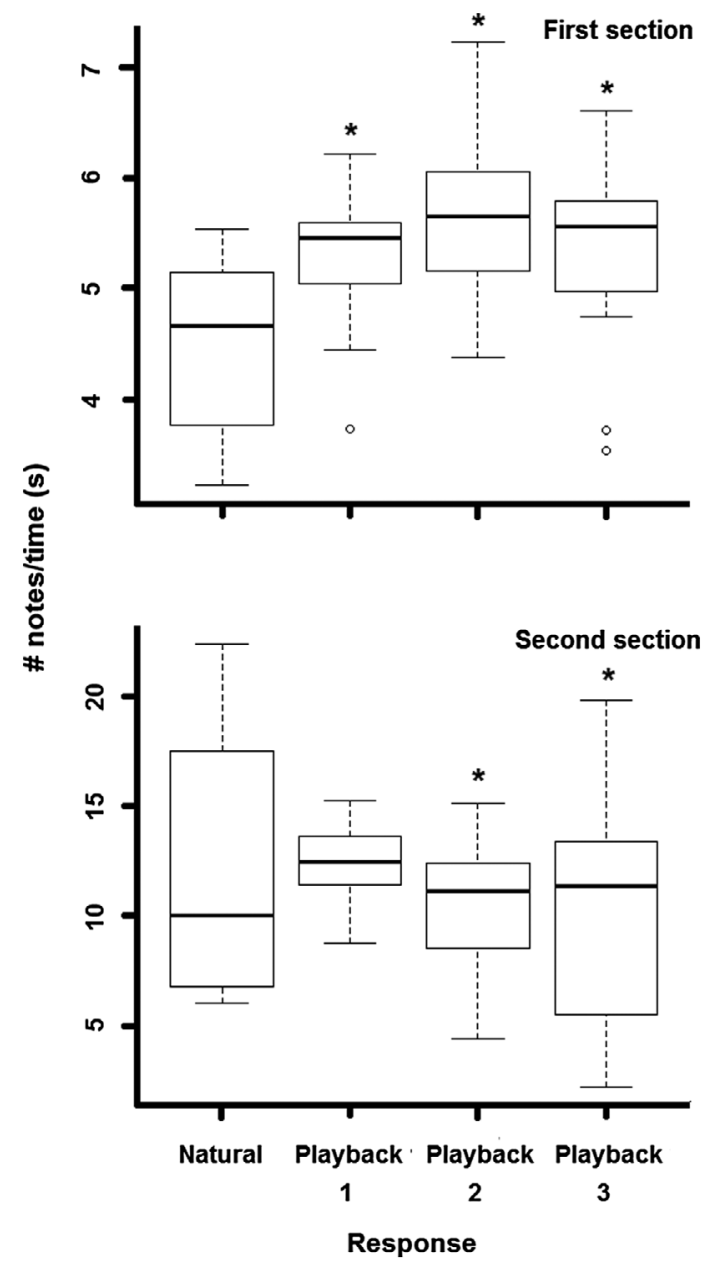

Figure 5. Variation of the number of notes sung over time in natural duets (unprovoked duets) and duets provoked by playbacks in the Large-footed finch.

Note: Asterisk $\left(^{*}\right)$ indicates $p$-value $<0.05$ when comparing each playback against natural duets.

Table 4. Comparison of acoustical variables between natural duets (unprovoked duets) and duets elicited by playbacks in the Large-footed finch.

\begin{tabular}{lccc}
\hline Acoustical variables & F-value & DF & Probability \\
\hline Duration of the duet & 0.15 & 3,53 & 0.927 \\
First section of the duet & & & \\
High frequency & 1.22 & 3,50 & 0.314 \\
Maximum frequency & 0.03 & 3,50 & 0.994 \\
Number of notes/duration & 4.63 & 3,52 & 0.006 \\
Second section of the duet & & & \\
High frequency & 3.19 & 3,28 & 0.0389 \\
Maximum frequency & 2.88 & 3,28 & 0.0537 \\
Number of notes/duration & 3.37 & 3,30 & 0.0314 \\
\hline
\end{tabular}

When compared to an unprovoked duet, pairs of Large-footed finches changed the characteristics of some acoustical variables in response to playbacks: high frequency in 
the second section of the duet, and the number of notes/duration in both sections of the duet. These changes in the acoustical characteristics of the duet could suggest an aggressive response to potential competitors (playbacks), considering that pairs behaved more actively and moved constantly during their responses to these playback trials. In Australian magpie larks, Hall and Magrath (2007) found that pairs modify the temporal characteristics of their duets in response to variation in the characteristics of the playbacks they were using to elicit a response, such as percentage of overlapping and temporal synchronization.

Further experiments are necessary to determine the role of temporal synchronization, acoustic frequency coordination and the ability to modify acoustic parameters during duetting on this species. Thus, understanding how and why birds coordinate their elements during duetting is essential to understand the evolution of duetting and its possible role in sexual selection, individual quality and resource defence.

\section{Acknowledgements}

We thank Luis Sandoval for his advice in analysis of duet synchrony, and Federico Valverde, Nidia Corrales and Miguel Esquivel for logistic support during the entire study period. We also thank three anonymous reviewers for very helpful comments on previous versions of the paper. We also thank William Eberhard and Johel Chaves for their valuable comments on the manuscript. For this study, we received financial support from the "Fondo Alexander F. Skutch, para la investigación ornitológica" (Asociación ornitológica de Costa Rica).

\section{Disclosure statement}

No potential conflict of interest was reported by the authors.

\section{Funding}

This work was supported by the "Fondo Alexander F. Skutch, para la investigación ornitológica" (Asociación ornitológica de Costa Rica).

\section{References}

Bioacoustics Research Program. 2011. Raven Pro: Interactive Sound Analysis Software (version 14) [Computer software]. Ithaca (NY): The Cornell Lab of Ornithology.

Brumm H, Slater P. 2007. Animal communication: timing counts. Curr Biol. 17:R521-R523.

Cator LJ, Arthur BJ, Harrington LC, Hoy RR. 2009. Harmonic convergence in the love songs of the dengue vector mosquito. Science. 323:1077-1079.

Dahlin C, Benedict L. 2013. Angry birds need not apply: a perspective on the flexible form and multifunctionality of avian vocal duets. Ethology. 119:1-10.

Douglas SB, Mennill DJ. 2010. A review of acoustic playback techniques for studying avian vocal duets. J Field Ornithol. 81:115-129.

Farabaugh S. 1982. The Ecological and Social Significance of Duetting. In: Kroodsma DE, Miller $\mathrm{EH}$, editors. Acoustic Communication in Birds, Volume 2: Song Learning and its Consequences. Academic Press. p. 85-124

Fitzsimmons LP, Foote JR, Ratcliffe LM, Mennill DJ. 2008. Frequency matching, overlapping and movement behaviour in diurnal countersinging interactions of black-capped chickadees. Anim Behav. 75:1913-1920. 
Graham BA, Sandoval L, Dabelsteen T, Mennill DJ. 2016. A test of the acoustic adaptation hypothesis in three types of tropical forest: degradation of male and female Rufous-and-white Wren songs. Bioacoustics. 26:37-61.

Hall M. 2004. A review of hypotheses for the functions of avian duetting. Behav Ecol Sociobiol. 55:415-430.

Hall M. 2009. Chapter 3: a review of vocal duetting in birds. Adv Study Behav. 40:67-121.

Hall M, Magrath R. 2007. Temporal coordination signals coalition quality. Curr Biol. 117:406-407. Langmore N. 1998. Functions of duet and solo songs of female birds. Trends Ecol Evol. 13:136-140. Logue D. 2005. Cooperative defense in duet singing birds. Cognit, Brain, Behav. 9:497-510.

Logue D. 2007. How do they duet? Sexually dimorphic behavioural mechanisms structure duet songs in the black-bellied wren. Anim Behav. 73:105-113.

Marshall-Ball L, Mann N, Slater PJB. 2006. Multiple functions to duet singing: hidden conflicts and apparent cooperation. Anim Behav. 71:823-831.

Maynard DF, Ward KA, Doucet SM, Mennill DJ. 2012. Calling in an acoustically competitive environment: duetting male long-tailed manakins avoid overlapping neighbours but not playback simulated rivals. Anim Behav. 84:563-573.

Naguib M, Mennill DJ. 2010. The signal value of birdsong: empirical evidence suggests song overlapping is a signal. Anim Behav. 80:e11-e15.

Pennetier C, Warren B, Dabiré KR, Russell IJ, Gibson G. 2010. "Singing on the Wing” as a Mechanism for Species Recognition in the Malarial Mosquito Anopheles gambiae. Curr Biol. 20:131-136.

R Core Team. 2012. R: A language and environment for statistical computing. Vienna: R Foundation for Statistical Computing. ISBN 3-900051-07-0. Available from: http://www.R-project.org/

Sandoval L, Méndez C, Mennill D. 2016. Vocal behavior of White-eared ground-sparrows (Melozone leucotis) during the breeding season: repertoires, diel variation, behavioura contexts, and individual distinctiveness. J Ornithol. 157:1-12.

Searcy WA, Beecher MD. 2009. Song as an aggressive signal in songbirds. Anim Behav. 78:1281-1292. Smith WJ. 1994. Animal duets: forcing a mate to be attentive. J Theor Biol. 166:221-223.

Stiles FG, Skutch A. 2007. Guía de Aves de Costa Rica. Santo Domingo de Heredia: Instituto Nacional de Biodiversidad (INBio).

Suthers R, Goller F, Pytte C. 1999. The neuromuscular control of birdsong. Philos Trans R Soc London Ser B. 354:927-939.

Todt D, Naguib M. 2000. Vocal interactions in birds: the use of song as a model in communication. Adv Study Beha. 29:247-296.

Trejos-Araya C, Barrantes G. 2014. Natural history and acoustic repertoire of the Large-footed finch (Pezopetes capitalis), an endemic, highland bird of Costa Rica and western Panama. Ornitol Neotrop. 25:261-271.

Zar JH. 2010. Biostatistical analysis. 5th ed. Upper Saddle River (NJ): Prentice Hall. 